\title{
PROGESTERONE AND OESTRONE LEVELS IN THE GONADS AND PYLORIC CAECA OF THE MALE SEA STAR ASTERIAS RUBENS: A COMPARISON WITH THE CORRESPONDING LEVELS IN THE FEMALE SEA STAR
}

\author{
P. A. Voogt and S. J. Dieleman* \\ Laboratory of Chemical Animal Physiology, State University of Utrecht, 8 Padualaan, 3508 TB Utrecht, \\ The Netherlands. Telephone: $030-532578$ and ${ }^{*}$ Clinic for Obstetrics, A.I. and Reproduction, Veterinary \\ Faculty, State University of Utrecht, 7 Yalelaan, 3508 TD Utrecht, The Netherlands
}

(Received 28 March 1984)

\begin{abstract}
Leveis of progesterone and oestrone were estimated by means of RIA in the gonads and pyloric caeca of male specimens of Asterias ruhens throughout the reproductive cycle.

2. The patterns obtained appeared to be sex-specific on comparison with those of female specimens of $A$. rubens and it was concluded that progesterone and oestrone in the testes are involved in the regulation of gametogenesis.

3. The levels of progesterone in the pyloric caeca were about ten times higher than those in the testes; in the same sequence levels of oestrone were only slightly higher.

4. The onset of a new reproductive cycle, taking the abrupt decrease of the pyloric caeca-index as a marker, coincides with a strong decrease of the progesterone level $(P \ll 0.001)$ and an increase of the oestrone level $(P<0.01)$ in the pyloric caeca.

5. It is supposed that progesterone and oestrone in the pyloric caeca are concerned with making available the materials required for gametogenesis.
\end{abstract}

\section{INTRODUCTION}

In recent years the presence and the metabolism of steroids in the gonads and pyloric caeca of the female sea star Asterias rubens have been studied extensively. Dieleman and Schoenmakers (1979) demonstrated by radioimmunoassay (RIA) the presence of progesterone and oestrone in these organs in agreement with earlier reports on the presence of progesterone (Botticelli et al., 1960, 1961; Ikegami et al., 1971) and of substances with oestrogen-like activity based on bioassays (Steidle. 1930; Donahue, 1940; Hagerman et al., 1957; Botticelli et al., 1960, 1961) in the ovaries of other echinoderms.

In vitro studies showed that the gonads and pyloric caeca of female $A$. rubens are able to synthesize $C_{21}$ steroids from cholesterol (Schoenmakers, 1979) and $\mathrm{C}_{14}$-steroids from progesterone (Schoenmakers and Voogt, 1980). Androstenedione was metabolized into other $\mathrm{C}_{19}$-steroids, but no evidence was obtained for the production of oestrogens (Schoenmakers and Voogt, 1981), which was in agreement with earlier findings of Colombo and Belvedere (1976). Actually till now, no data are available on oestrogen formation in any invertebrate.

Schoenmakers and Dieleman (1981) reported varying levels of progesterone and oestrone in the gonads and the pyloric caeca of female $A$. rubens and related these differences to the stages of the reproductive cycle as distinguished by Schoenmakers et al. (1984).

Since all reports until now concern only the gonads of female echinoderms nothing is known about the levels of steroids in male specimens.

This paper will be the first one dealing with steroid levels in male sea stars. For obvious reasons in this orientation the same steroids were estimated as had been determined earlier for female specimens (Schoenmakers and Dieleman, 1981). Presented are the levels of progesterone and oestrone in the gonads and pyloric caeca of male specimens of A. rubens collected at different times of the year, and the course of these levels is compared with that in female animals.

\section{MATERIALS AND METHODS}

\section{Animals}

Adult specimens of Asterias rubens were collected from the Wadden Sea population (The Netherlands) at set intervals over a one year period. The animals were kept in recirculating sea-water at $6 \mathrm{C}$ for three days in which no food was given to have the alimentary canal freed of food residues, and then processed. The male animals used in this study were from the same samples as the female animals used in an earlier study (Schoenmakers and Dieleman, 1981).

\section{Dissection of animals}

Animals were dissected in the usual way, and the gonads and pyloric caeca were taken out (only non-parasitized animals were used). Sex was determined by microscopical examination of a squashed piece of gonadal tissue. The testes and pyloric caeca of at least four male animals of each sample were stored after homogenization at $-25 \mathrm{C}$ until assayed.

\section{Estimation of stcroids}

Progesterone and oestrone levels were estimated in the homogenates by previously validated RIA methods (Dieleman and Schoenmakers, 1979). The antiserum (S74 B7) for the RIA of progesterone against $11 \alpha$-hydroxyprogesteronehemisuccinate BSA conjugates was raised in sheep. The 
antiserum (7604-7 40) for the RIA of oestrone against oestrone-t-keto-oxime BSA conjugates was raised in rabbits.

Progesterone and oestrone were extracted from the homogenates with $n$-hexane $\left(99.5^{\circ}\right.$; Merck AG, Darmstadt, FRG) and twice distilled benzene (Uvasol, Merck $A G)$, respectively.

The intra- and interassay coefficients of variation were $\leqslant 11$ and $\leqslant 12 \%(n \geqslant 12)$, respectively, and the sensitivity was at least $7 \mathrm{pg} /$ tube.

\section{Statistics}

Analysis of variance of the data was performed and differences were tested by means of a modified $t$-test, a multiple comparison technique based on the Bonferroni inequality (Miller, 1980). When variances were unequal differences were tested according to Box 13.3 (Sokal and Rohlf, 1969).

\section{RESULTS AND DISCUSSION}

The mean organ indices $( \pm S D)$ per sample of the testes and the pyloric caeca are given in Table 1 . The gonad-index is low in June, August and September, increases slowly during October and November, and sharply from November until January and in March and April. Then there is an abrupt fall between April and June resulting from the shedding of the gametes. The pyloric caeca-index is high in June and August, falls abruptly in September, decreases gradually during the remaining part of the annual cycle, and is high again in June of the following year.

The antisera used against progesterone and oestrone are highly specific and therefore it is concluded that progesterone and oestrone are present in the gonads and pyloric caeca of male $A$. rubens as has been reported for female animals (Dieleman and Schoenmakers, 1979).

The levels of steroids in these organs are given as nanogram steroid per gram fresh weight (Table 2).
Table 1. Mean organ indices $( \pm \mathrm{SD})$ per sample of male specimens

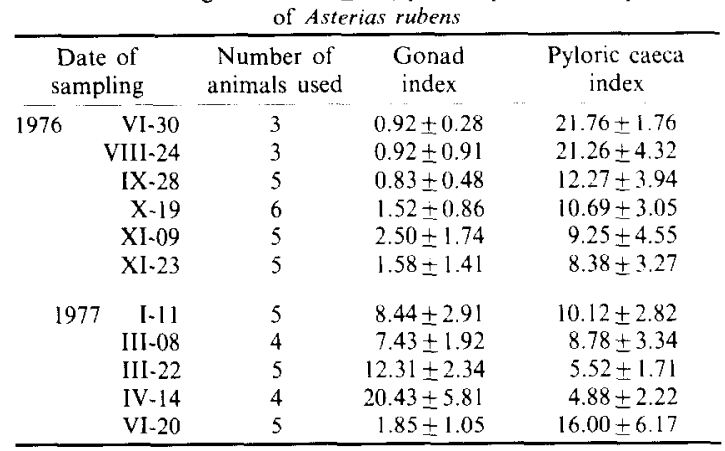

\section{Steroids in the gonads}

The progesterone level is low in June and August (Tablc 2, Fig. 1), is higher in September with a gradual decrease until the beginning of November, reaches maximum values at the end of November, and is rather constant from January until April. The mean progesterone level at November 23 is higher than the mean levels of the periods before and after that date, but differences are not statistically significant.

In Fig. 2 these progesterone levels are compared with those for female animals collected at the same time, at the same location and assayed in the same way (Schoenmakers and Dieleman, 1981). Obviously the courses of the level during the year are quite different, although they have in common that a low level is reached in both sexes at November 9 (in females this is even the lowest level observed).

During the period preceding November 9, progesterone levels in the testes are lower than the corresponding levels in the ovaries whereas the reverse holds for the period after November 9; after

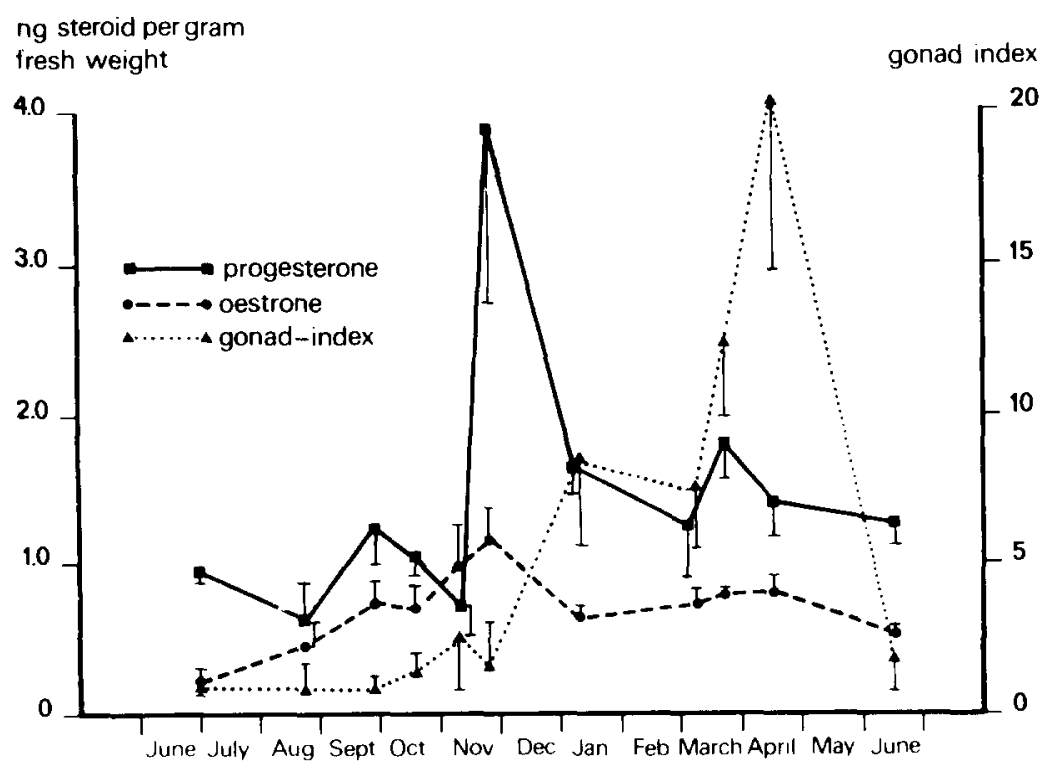

1976 date of sample 1977

Fig. 1. Mean ( \pm SEM) levels of progesterone and oestrone per sample in the testes and the mean gonad index $( \pm \mathrm{SD})$ per sample of Asterias rubens during the reproductive cycle. Levels are expressed as ng/g fresh weight. Number of animals as given in Table 1 . 
Table 2. Mean ( \pm SEM) progesterone and oestrone levels per sample of male specimens of Asterias rubens expressed as $\mathrm{ng} / \mathrm{g}$ fresh weight

\begin{tabular}{|c|c|c|c|c|c|}
\hline \multirow{2}{*}{\multicolumn{2}{|c|}{ Date of sampling }} & \multicolumn{2}{|c|}{ Testes } & \multicolumn{2}{|c|}{ Pyloric caeca } \\
\hline & & Progesterone & Oestrone & Progesterone & Oestrone \\
\hline \multirow[t]{6}{*}{1976} & VI-30 & $0.96 \pm 0.03$ & $0.29 \pm 0.10$ & $23.3 \pm 1.8$ & $1.72 \pm 0.06$ \\
\hline & VIII-24 & $0.62 \pm 0.25$ & $0.48 \pm 0.17$ & $22.3 \pm 0.4$ & $0.98 \pm 0.17$ \\
\hline & $1 X-28$ & $1.28 \pm 0.24$ & $0.77 \pm 0.16$ & $14.9 \pm 3.5$ & $2.03 \pm 0.12$ \\
\hline & $X+19$ & $1.07 \pm 0.13$ & $0.71 \pm 0.16$ & $13.6 \pm 1.6$ & $1.66 \pm 0.14$ \\
\hline & $\times 1-09$ & $0.75 \pm 0.17$ & $1.00+0.32$ & $8.8 \pm 2.1$ & $1.48 \pm 0.10$ \\
\hline & $\mathrm{XI}-23$ & $3.84 \pm 1.10$ & $1.18 \pm 0.20$ & $10.3 \pm 2.0$ & $1.41 \pm 0.11$ \\
\hline \multirow[t]{5}{*}{1977} & I-1I & $1.66 \pm 0.15$ & $0.64 \pm 0.07$ & $12.9 \pm 1.2$ & $1.35 \pm 0.11$ \\
\hline & $111-08$ & $1.29 \pm 0.35$ & $0.73 \pm 0.11$ & $9.8 \pm 0.7$ & $1.04 \pm 0.17$ \\
\hline & $111-22$ & $1.79 \pm 0.19$ & $0.79 \pm 0.05$ & $12.3 \pm 3.8$ & $0.90 \pm 0.22$ \\
\hline & IV -14 & $1.42 \pm 0.28$ & $0.82 \pm 0.11$ & $12.0 \pm 1.4$ & $0.51 \pm 0.18$ \\
\hline & VI 20 & $1.26 \pm 0.17$ & $0.54 \pm 0.06$ & $13.5 \pm 2.2$ & $1.53 \pm 0.18$ \\
\hline
\end{tabular}

Number of animals as in Table 1.

spawning (June) the former situation seems to be restored. In ovaries progesterone levels are higher in the period before November 9 than in the period after that date, whereas in testes the levels show an inverse course.

The sex-specificity of the pattern of the progesterone level in the gonads of both sexes during the yedr, supports the idea that progesterone is involved in the regulation of sex-specific processes going on in the gonads, particularly of gametogenesis.

The oestrone level in the testes shows a picture rather similar to that of progesterone (Table 2, Fig. 1): the level is low in the first part of the annual cycle, reaches a maximum value at the end of November, and shows little variation after that time, As was found for progesterone the oestrone level at 23 November is not significantly different from the mean level of the periods before and after that date.

In Fig. 3 these oestrone levels are compared with those reported for the ovaries of female animals
(Schoenmakers and Dieleman, 1981). Essentially, the same picture is obtained as in Fig. 2.

In the first part of the annual cycle oestrone level is higher in the ovaries, whereas from November until spawning it is slightly higher in the testes. The former situation seems to be restored after spawning. Therefore the course of the oestrone level in the gonads during the annual cycle scems to be sex-specific, too. On the same grounds it is supposed that also oestrone is involved in the process of gametogenesis.

In Fig. 1 levels of progesterone and oestrone are shown together with the gonad-indices. Peak levels of progesterone and oestrone are reached some time after the onset of testes growth and are followed by a sharp increase in the growth. This also suggests that progesterone and oestrone are concerting in the regulation of gametogenesis.

Progesterone levels in the testes are higher than those of oestrone. However, at 9 November, thus just prior to the peak values for both steroids, the level of

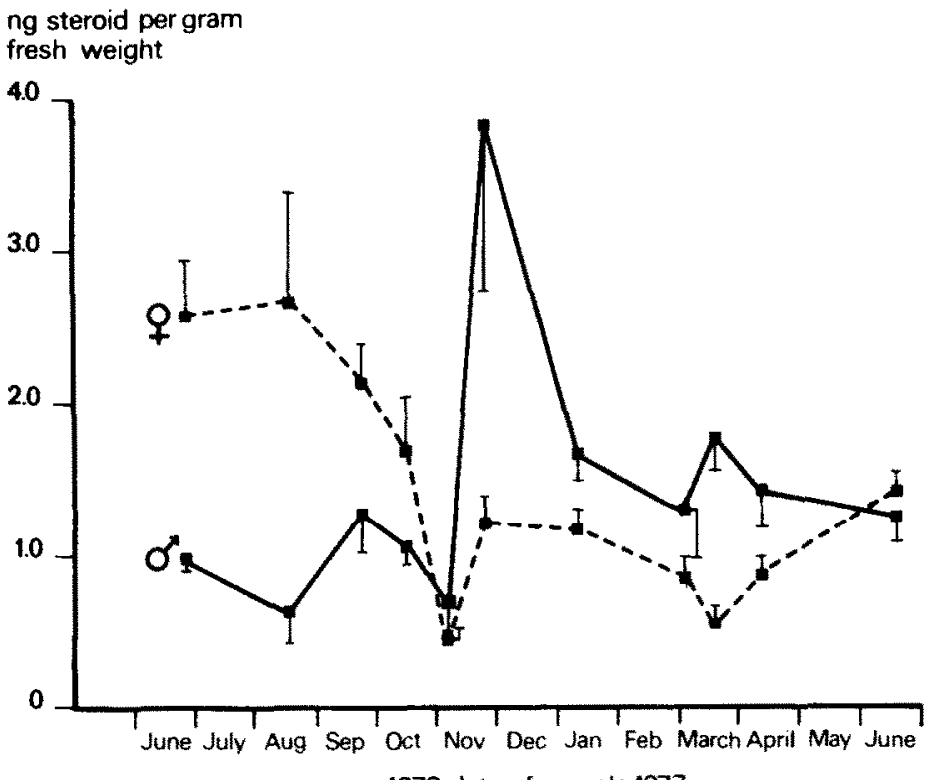

1976 date of sample 1977

Fig. 2. Mean ( \pm SEM) levels of progesterone per sample in the testes and ovaries of Asterias rubens during the reproductive cycle. Levels are expressed as $\mathrm{ng} / \mathrm{g}$ fresh weight. Number of male animals as given in Table 1. Data on the female animals are after Schoenmakers and Dieleman (1981). 


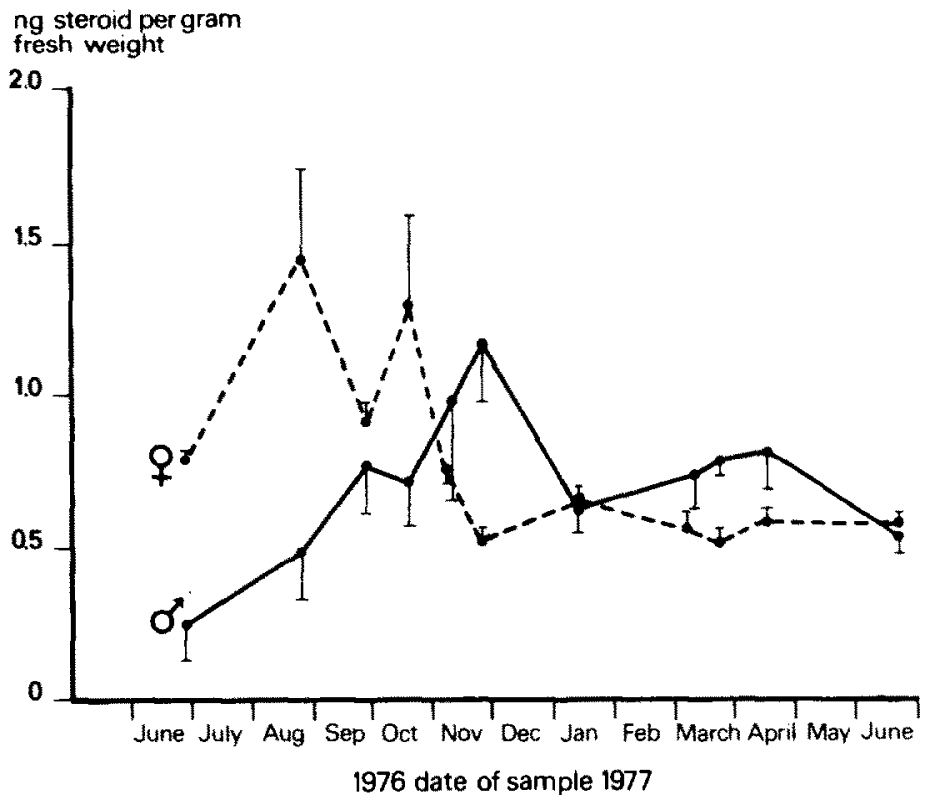

Fig. 3. Mean ( \pm SEM) levels of oestrone per sample in the testes and ovaries of Asterias rubens during the rcproductive cycle. Levels are expressed as ng per $g$ fresh weight. Number of male animals as given in Table 1. Data on female animals are after Schoenmakers and Dieleman (1981).

oestrone exceeds that of progesterone. The same phenomenon was observed at the same date in the ovaries of the female sea stars under comparison. Particularly, when the concerting of progesterone and oestrone in the regulation of gametogenesis might be expressed in terms of a hormone balance, the reversal of the oestrone/progesterone ratio may be of great importance in triggering special processes. This aspect will be studied further.

\section{Steroids in pyloric caeca}

The levels of progesterone and of oestrone in male pyloric caeca (Table 2) are one order and slightly higher, respectively, than those in the testes. The conversion rate of progesterone into other steroids during the year is higher in the pyloric caeca than in the testes (Voogt, unpublished data). This, together with the 10-fold higher level of progesterone, indicates that, like in females, the pyloric caeca are more important organs for the synthesis of progesterone than the gonads.

The progesterone level in pyloric caeca (Table 2, Fig. 4) is high in June and August, decreases sharply during September and October, reaches a minimum at 9 November, and remains rather constant after that date.

The oestrone level is high in June and August, reaches maximum values in September, decreases gradually after that date, reaching a minimum value (about one fourth of the maximal value) just prior to spawning, and is high again after spawning.

The course of the levels of progesterone and oestrone in the pyloric caeca during the year differs considerably from that in the testes, which suggests that the functions of these steroids in the two organs are different.

Progesterone levels in pyloric caeca are lower in males than in females $(P<0.001)$, whereas the reverse holds for the oestrone levels $(P<0.02)$.

The progesterone level in pyloric caeca of female sea stars was high during stage 1 and 2 and decreased abruptly at the beginning of stage 3 (late growth and partial maturation; Schoenmakers et al., 1984) and increased to the former level at the end of this stage (Schoenmakers and Dieleman, 1981). Since stage 3 is characterized by a rapid growth of the ovaries, the change in the progesterone level in the pyloric caeca may be related to making available materials stored in these organs for ovarian growth. Unfortunately, a detailed division of the reproductive cycle of male gonads into stages is not available. Table 1 shows that the pyloric caeca index drops sharply between August and September, whereas at that time no change in the gonad-index occurs. This phenomenon is quite common and has been observed both in male and female sea stars (Van der Plas and Oudejans, 1982). It means that materials have been released from the pyloric caeca but have not yet been deposited in the gonads. This indicates that a new reproductive cycle has started at that time and it is logical to suppose that-if steroids are involved in the regulation of reproduction-this start is reflected in the levels of these steroids. Statistical analysis shows that the mean progesterone level of June and August is higher than that of the remaining part of the year $(P \ll 0.001)$. The progesterone level in September is lower than the mean level of June and August $(P<0.05)$, but is not different from the mean level of the second part of the year. Furthermore the oestrone level in September is higher than the mean level of June and August $(P<0.01)$ and of the second part of the year $(P<0.001)$. Thus the start of a new reproductive cycle in male sea stars coincides with significant changes in the levels of progesterone and oestrone in the pyloric caeca. 


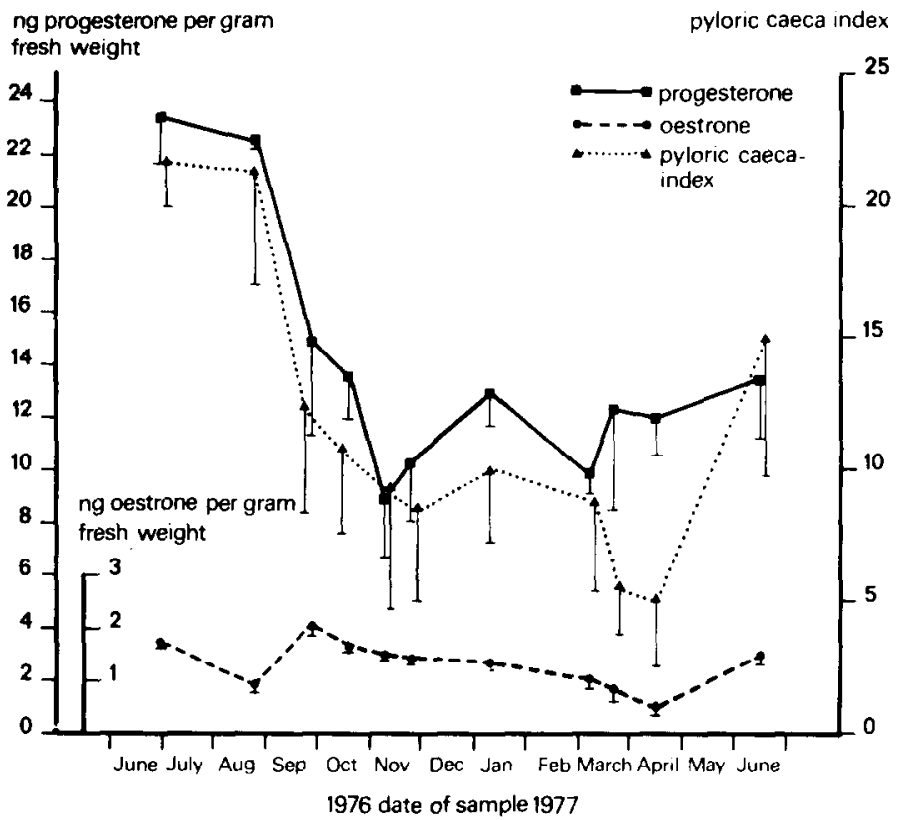

Fig. 4. Mean ( \pm SEM) levels of progesterone and oestrone per sample in the pyloric caeca and the mean pyloric caeca index $( \pm \mathrm{SD})$ per sample of male Asterias rubens during the reproductive cycle. Levels are expressed as ng per $\mathrm{g}$ fresh weight. Number of animals as given in Table 1 .

In the testes the level of progesterone in September is not different from the mean level of June and August $(0.05<P<0.1)$; the corresponding levels of oestrone are marginally different from each other $(P=0.05)$. This means that the onset of a new reproductive cycle is not clearly reflected in significant changes in the levels of progesterone and oestrone in the testes.

Further research will be necessary to clarify the function and the interplay of steroids in the gonads and pyloric caeca of both male and female sea stars.

Acknowledgements - The authors wish to thank Miss H. ten Brinke for her technical assistance, Miss Angela de Lange for typrewriting the manuscript and $\mathrm{Mr} \mathbf{J}$. J. van der Vlis for drawing the figures.

\section{REFERENCES}

Botticelli C. R., Hisaw F. I.., Jr. and Wotiz H. H. (1960) Estradiol-17 $\beta$ and progesterone in ovaries of starfish (Pisaster ochraceus). Proc. Soc. exp. Biol. Med. 103, 875-877.

Botticelli C. R., Hisaw F. L., Jr. and Wotiz H. H. (1961) Estrogens and progesterone in the sea urchin (Strongylocentrotus franciscanus) and pecten (Pecten hericius). Proc. Soc. exp. Biol. Med. 106, 887-889.

Colombo L. and Belvedere P. (1976) Gonadal steroidogenesis in echinoderms. Gen. comp. Endocr. 29, 255-256.

Dieleman S. J. and Schoenmakers H. J. N. (1979) Radioimmunoassays to determine the presence of progesterone and estrone in the starfish Asterias rubens. Gen. comp. Endocr. 39, 534-542.

Donahue J. K. (1940) Occurrence of estrogens in the ovaries of certain marine invertebrates. Endocrinology 27, 149-152.
Hagerman D. D., Wellington F. H. and Villee C. A. (1957) Estrogens in marine invertebrates. Biol. Bull. 112, $180-183$.

Ikegami S., Shirai H. and Kanatani H. (1971) On the occurrence of progesterone in ovary of the starfish, Asterias amurensis. Dobutsugaku Zasshi 80, 26-28.

Miller R. G., Jr. (1980) Simultaneous Statistical Inference. McGraw-Hill, New York.

Schoenmakers H. J. N. (1979) In vitro biosynthesis of steroids from cholesterol by the ovaries and pyloric caeca of the starfish Asterias rubens. Comp. Biochem. Physiol. 63B, 179-184.

Schoenmakers H. J. N. and Dieleman S. J. (1981) Progesterone and estrone levels in the ovaries, pyloric caeca, and perivisceral fluid during the annual reproductive cycle of starfish, Asterias rubens. Gen. comp. Endocr. 43, 63-70.

Schoenmakers H. J. N. and Voogt P. A. (1980) In vitro biosynthesis of steroids from progesterone by the ovaries and pyloric caeca of the starfish Asterias rubens. Gen. comp. Endocr. 41, 408-416.

Schoenmakers H. J. N. and Voogt P. A. (1981) In vitro binsynthesis of steroids from androstenedione by the ovaries and pyloric caeca of the starfish Asterias rubens. Gen. comp. Endocr. 45, 242-248.

Schoenmakers H. J. N., Goedhart M. J. and Voogt P. A. (1984) Biometrical and histological aspects of the reproductive cycle of the ovaries of Asterias rubens (Echinodermata). Biol. Bull 166, 320-348

Steidle H. (1930) Über die Verbreitung des weiblichen Sexualhormones. Arch. exp. Path. Pharmak. 157, 89.

Sokal R. R. and Rohlf F. J. (1969) Biometry: The Principles and Practice of Statistics in Biological Research. Freeman, San Francisco.

Van der Plas A. J. and Oudejans R. C. H. M. (1982) Changes in the activities of selected enzymes of intermediary metabolism in the pyloric caeca and ovaries of Asterias rubens during the annual reproductive cycle. Comp. Biochem. Physiol. 71B, 379-385. 